\title{
Urban Growth Boundary and Housing Prices: The Case of Knox County, Tennessee $^{+}$
}

\author{
Seong-Hoon Cho, Zhuo Chen, and Steven T. Yen*
}

\begin{abstract}
This study tests the hypothesis that a higher present value of expected rental stream of undeveloped land in the urban growth area influences the effect of the Urban Growth Boundary (UGB) on the values of newly developed houses in Knoxville and Knox County, Tennessee. We estimate a version of the Box-Cox (BC) transformed hedonic housing price model, which accommodates both nonnormality and heteroskedasticity in the stochastic error term. The finding of this study verifies the premise that the values of newly developed houses after the implementation of a UGB are likely to be higher within the urban growth area than those outside, all other things equal.
\end{abstract}

Key Words: Box-Cox transformation; Hedonic price; Knoxville; Urban growth boundary

JEL Classifications: C21, O18, R52

\section{INTRODUCTION}

Responding to concerns over sprawl, high concentrations of ground-level ozone in all of Tennessee's major cities as well as the Smoky Mountains (VCEMS, 2002; NOAA, 2003), and fallout from local annexation battles, the State of Tennessee adopted the Growth Policy Act (henceforth the Act) in 1998. Among other things, the Act requires that all Tennessee municipalities and counties (except counties with a metropolitan form of government) collaborate in defining urban growth boundaries (UGBs). For a state in a region that has traditionally been leery of land use regulations, the Act was a bold and unexpected move (Porter, 2002). In fact, at the time of the adoption, Tennessee was only one of three states to have adopted statewide policies mandating UGBs for local governments. ${ }^{1}$

The City of Knoxville, at the center of a metropolitan area in eastern Tennessee, adopted a UGB in 2001. Based on Public Chapter 1101, the county, and the town and city within it, identified three classifications of land: rural areas, urban growth areas (UGAs), and planned growth areas (PGAs). The rural areas include land to be preserved for farming, recreation, and other non-urban uses. The UGA is reasonably compact, but adequate to accommodate the entire city's expected growth for the next 20 years. PGAs are large enough to accommodate urban

\footnotetext{
+ The authors thank William M. Park, Christopher D. Clark, and Frank O. Leuthold for helpful comments. Thanks are also due to Tim Kuhn and Gretchen Beal of Knoxville-Knox County Metropolitan Planning Commission and Keith G. Stump of KnoxvilleKnox County-Knoxville Utilities Board Geographic Information System for providing urban growth boundary, school district, and housing sales data.

* Cho and Yen are affiliated with the Department of Agricultural Economics at The University of Tennessee. Chen is affiliated with the Chicago Center of Excellence in Health Promotion Economics at The University of Chicago.

Contact author: Seong-Hoon Cho, 314D Morgan Hall, University of Tennessee, Knoxville, TN 37996-4518, Email: scho9@utk.edu.

${ }^{1}$ Oregon adopted the growth management legislation in 1973 and Portland, Oregon, adopted a UGB in 1979. Washington passed the Growth Management Act in 1990 and Clark County, Washington, introduced a UGB in 1995.
}

(C) Southern Regional Science Association 2010.

ISSN 1553-0892

SRSA, 1601 University Avenue, P.O. Box 6025, Morgantown, West Virginia 26506-6025, USA. 
growth expected to occur in unincorporated areas over the next 20 years (Metropolitan Planning Commission, 2001).

An UGB is a mapped line that separates lands for concentrated development from those where development will be discouraged or prohibited. Typically, facilities and services necessary for urban development are provided within the boundary, while service extensions outside the boundary are restricted. The purposes of Knoxville's UGB are: (1) to encourage a reasonably compact pattern of development, (2) to promote expansion of the local economy, (3) to offer a wide range of housing choices, and (4) to coordinate the actions of the public and private sectors, particularly with regard to provision of adequate roads, utilities, schools, drainage, and other public facilities and services (MPC, 2001).

Like the case in Portland, the UGA of Knoxville is designed not only to be reasonably compact, but also adequate to accommodate the city's expected growth for the next 20 years. Unlike Portland, however, Knoxville does not provide public facilities and subsidies in the UGA to encourage development. Further, the UGB of Knoxville was drawn in response not only to concerns over growth management, but also to the fallout from local annexation battles. As a result of such battles, the Knoxville city government has the right to annex land parcels in the UGA without the consent of land owners. Once the property is annexed, the property owners have to pay city property tax and receive the city's public services (e.g., garbage pick-up and emergency services).

There are no clear legal restrictions imposed by the UGB adoption on land use in Knox County. The Metropolitan Planning Commission documented that in the UGB of Knoxville, "any land use permitted in the Zoning Ordinance of the appropriate jurisdiction is permitted, subject to all requirements of that jurisdiction" (MPC, 2001, Section 1, Policies paragraph 5.2). Although the UGB code does not differentiate requirements of the jurisdiction, the plan differentiates guidelines for rezoning decisions which may be crucial conditions for issuing permits for new residential developments. Details about the rezoning decision within and outside of the UGB can be found in the Public Chapter 1101 (MPC, 2001). In summary, rezoning conditions are more stringent outside of the UGB than in the UGA to encourage a reasonably compact pattern of development.

Knapp (1985) presented a theoretical framework for the role of UGBs on urban and nonurban land values, and found a significant impact of UGBs on land values in metropolitan Portland, Oregon. Nelson (1986) developed a theory of how urban containment programs like UGBs and greenbelt zoning should divide the regional land market into urban and rural components; he also provided evidence that amenity values created by greenbelts (i.e., amenities of green open space) might be reflected in gains in land values. Glaeser, Gyourko, and Saks (2006) presented a model that shows the effect of heterogeneity in housing supply on urban development. The empirical evidence is split as to whether the UGB has had any effects on housing prices in Portland, with some researchers concluding that market demand, not the boundary, has been the primary driver of housing prices (Downs, 2002), and others suggesting that the UGB has created an upward pressure on housing prices in Portland (Phillips and Goodstein, 2000; Cho, Wu, and Boggess, 2003).

Despite the substantial body of literature that has evaluated the UGB of Portland, Oregon, the UGB of Knoxville needs particular attention because of its unique features and uncertainties. The study of an UGB other than Portland's provides an interesting contrast with previous 
research on UGBs and brings additional insight for policymakers currently implementing or contemplating the use of UGBs in other communities across the country.

This study empirically measures the effect of the Knoxville UGB on housing prices. In order to lay the foundation for the empirical analysis, a theoretical framework is specified to motivate the hypothesis testing. Specifically, we test whether the present value of the expected rental stream in the UGA is higher than the expected rental stream outside the area by estimating a hedonic price model for houses built before and after the UGB and location inside and outside of the UGB in Knox County.

The extant literature on housing prices suggests that the error variance is related to lot size and age of the structure (e.g., Fletcher, Gallimore, and Mangan, 2000; Goodman and Thibodeau, 1995). Heteroskedasticity of the error terms can cause statistical inefficiency in parameter estimates and confound inferences. This study accounts for both non-normality and heteroskedasticity of the error terms by using a heteroskedastic Box-Cox (BC) model. Another important issue is raised regarding the spatial structure of housing values in the hedonic model (e.g., Anselin and Lozano, 2008). Most recently, a spatial heteroskedasticity and autocorrelation consistent (SHAC) estimator has been developed by Kelejian and Prucha (2007). The Box-Cox technique cannot easily be used in conjunction with the more complex spatial specification. Instead, median housing value by census-block group is included in the hedonic model to control for the effects of neighboring housing values. This is done to mitigate the effects of spatial dependence, but not to control for it.

\section{THEORETICAL FRAMEWORK}

Following Knapp (1985), the price of undeveloped land in the UGA and the price of undeveloped land outside of the area are, respectively:

$$
\begin{aligned}
& P_{n}^{i}=R_{u}+\frac{R_{u}}{(1+r)^{1}}+\ldots+\frac{R_{u}}{(1+r)^{x-1}}+\frac{R_{d}(t)}{(1+r)^{x}} \ldots \frac{R_{d}(t)}{(1+r)^{\infty}}, \\
& P_{n}^{o}=R_{u}+\frac{R_{u}}{(1+r)^{1}}+\ldots+\frac{R_{u}}{(1+r)^{x}}+\ldots+\frac{R_{u}(t)}{(1+r)^{y-1}}+\frac{R_{d}(t)}{(1+r)^{y}} \ldots \frac{R_{d}(t)}{(1+r)^{\infty}},
\end{aligned}
$$

where $x$ is the expected date of development within the boundary, $y$ is the expected date of development outside the boundary, $R_{u}$ is the return from undeveloped land (i.e., farmland and forest land), $R_{d}$ is the return from developed land, and $r$ is the discount rate. Because the rezoning conditions are more stringent outside of the UGB according to the Public Chapter 1101, $y$ should be greater than $x$. Assuming land values in developed areas will not vary across the UGB, the difference between the present value of the expected rental stream of undeveloped land inside and outside of the boundary due to the different expected dates of development by the rezoning condition is:

$$
P_{n}^{i}(t)-P_{n}^{o}(t)=\frac{\left[R_{d}(t)-R_{u}\right]}{(1+r)^{x}}+\frac{\left[R_{d}(t)-R_{u}\right]}{(1+r)^{x+1}} \ldots \frac{\left[R_{d}(t)-R_{u}\right]}{(1+r)^{y-1}}>0 .
$$

(C) Southern Regional Science Association 2010. 
The higher present value of expected rental stream of undeveloped land in the UGA should be reflected in higher premiums for the land prices of newly developed houses. Because of the higher land premiums in the UGA, the values of newly developed houses after the implementation of the UGB, ceteris paribus, are likely to be higher in the UGA than the outside.

\section{IDENTIFYING THE EFFECT OF UGBS ON HOUSING PRICES}

Identifying the effect of the UGB on housing prices is difficult because there is no available random control experiment. Bin and Polasky (2004) provided an identification strategy in examining the effect of Hurricane Floyd on housing prices in a hedonic price model; an interaction term between the floodplain variable (indicating areas being affected) and a postFloyd dummy variable (indicating houses sold after the hurricane) was included to capture the effects of flood hazards on property value. We follow this strategy given the similarities that the external factors of the UGBs and the flood hazards have on housing prices. Specifically, we create a similar interaction term between the location UGB variable (LUGB), indicating areas in or out of UGA and a time UGB variable (TUGB), indicating newly developed houses built and sold before or after the UGB implementation. This interaction term captures the effect of UGB on housing price after netting out the confounding time and location effects, testing the hypothesis of higher value for newly developed houses in the UGA since UGB implementation. Other interaction terms of the variable, indicating houses built and sold before or after UGB periods (with the variables indicating within or outside of the City of Knoxville and within or outside of town of Farragut), are used to capture the spillover effects of the UGB (see Figure 1 for an illustration of these areas).

Note that because the Act was passed in 1998, one might argue that real-estate markets would anticipate the imposition of the UGB between 1998 and 2001. Based on interviews with local realtors and planners about the issue, we have learned that the anticipation factor from the demand side is likely to be trivial. However, there might be a lag in realizing the present value of the expected rental streams in the higher premium of land price for newly developed houses. Land supply, accounting for the difference of the present value in and outside of the UGA may change instantaneously upon the creation of the UGB, but home buyers/sellers may have delayed reactions. In order to trace the price differences over time before and after the UGB implementation, year dummy variables are used.

\section{STUDY AREA AND DATA}

Knox County is located in East Tennessee, one of the three "Grand Divisions" in the state. The City of Knoxville is the county seat of Knox County. Knoxville includes 101 square miles of 526 square miles total for Knox County. Downtown Knoxville is 936 feet above the sea level. The Smoky Mountains, the most-visited National Park in the country and a large quantity of lake acreage (17 square miles of total water body developed by the Tennessee Valley Authority) are on Knoxvillians' doorstep.

The county has grown rapidly in recent years. During the 1980s, the population of Knox County increased by 5 percent. By the following decade, the population grew at a nearly tripled rate (14 percent), from 335,749 to 382,032 residents. The majority of the rapid growth has occurred in portions of West and North Knox County, while other areas have seen slow growths or declines. Specifically, population in the Southwest and Northwest County Sectors, defined by

(C) Southern Regional Science Association 2010. 


\section{FIGURE 1. Urban Growth Boundary in Knox County, Tennessee}

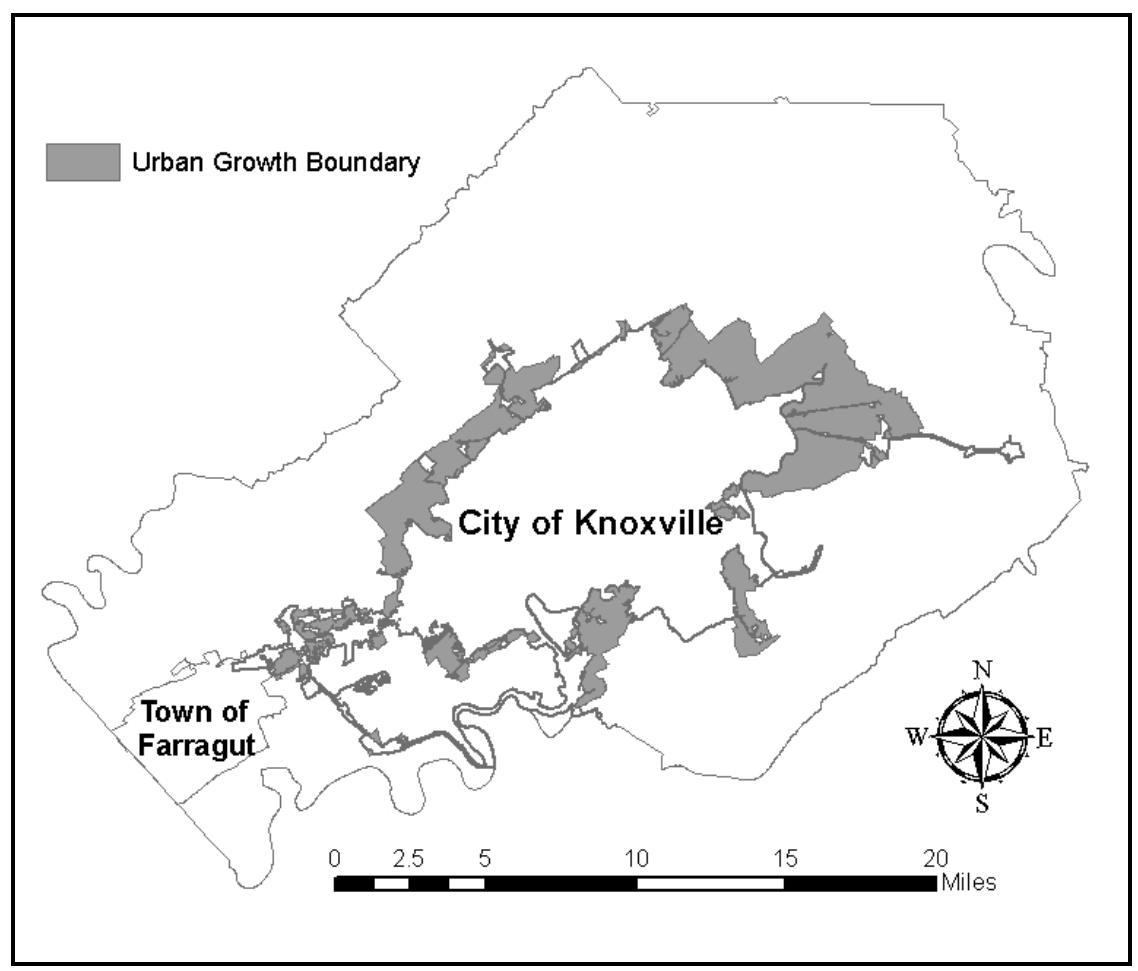

the Knoxville-Knox County Metropolitan Planning Commission, rose 36 percent and 29 percent, respectively, and accounted for 65 percent of the countywide increase between 1990 and 2000.

Our data contain newly developed single-family residential home sales records between January 1997 and December 2004, which include the prices of houses built and sold four years before and after the adoption of the UGB. The sample was limited to the sales transactions of newly developed houses because the difference in the present value of the expected rental streams due to the premium in undeveloped land value within the UGA should be reflected in newly developed houses.

The study area consists of 234 census-block groups in year 2000 boundaries. Normalized 1990 census data in 2000 boundaries and 2000 data were used at the census-block group level. The 1990 data were normalized to 2000 boundaries because the geographic definitions of boundaries changed between 1990 and 2000. The normalized data were created by a private data provider, GeoLytics. ${ }^{2}$ Information from these census-block groups was assigned to houses located within the boundaries of the block groups. The timing of the census and sales records did not match, except in 2000. The census information for the three years before 2000 (1997, 1998, and 1999) was generated by interpolation using 1990 and 2000 census data, while the census information for the four years after 2000 (2001, 2002, 2003, and 2004) was generated by extrapolation using the census data except the median housing value. Due to the potential

\footnotetext{
${ }^{2}$ Their normalization procedures are described on their website, http://www.geolytics.com/USCensus,Census-1990-Long-Form2000-Boundaries,Data,Methodology,Products.asp.
}

(C) Southern Regional Science Association 2010. 
endogeneity of median housing value with respect to housing price mentioned in the following Empirical Model section, a one-year lagged median housing value is used in the hedonic model.

Six key structural characteristics are used in this study: total finished square footage, lot size, age of structure, number of bedrooms, presence of a fireplace, and presence of all sided brick exterior. These control variables have been used to explain housing prices in the literature (e.g., Bin and Polasky, 2004; Chan, 2004; Mahan, Polasky, and Adams, 2000). As for the distance variables, Euclidean distances to the nearest golf course, to the West Town Mall, to the nearest railroad, to the nearest greenway, to the nearest lake or reservoir, and to the center of the business district are included to measure the socioeconomic and environmental amenities or disamenities of distance factors on housing values. Although travel distance is a more accurate measure, Euclidean distance can be used as a proxy for accessibility (McMillen, 1989; Hushak, 1975). Distances are calculated using the shape files of various location variables from the Environmental System Research Institute's Data \& Maps 2004, ArcGIS 9.0. Following school accountability and housing value studies (Kane, Staiger, and Samms, 2003), average American College Testing (ACT) scores are included for the twelve high school districts for the year of each sale transaction.

Housing sale prices are adjusted to 2000 dollars to account for real estate market fluctuations in the Knoxville metro region. This adjustment is made using the annual housing price index (HPI) for the Knoxville Metro Statistical Area, obtained from the Office of Federal Housing Enterprise Oversight (OFHEO, 2006). This adjustment controls for price variations due to time specific unobservable characteristics of the local real estate market that are unrelated to the UGB adoption (e.g., housing price changes due to speculation or a favorable lending environment and regional variables that may impact housing demand). Similarly, the 1990 census data are adjusted to 2000 dollars using the Consumer Price Index from the Bureau of Labor Statistics (BLS). Following BLS guidelines (2006), the median housing value of 1990 was multiplied by 1.28 and per capita income of 1990 was multiplied by 1.30 to adjust to 2000 dollar values. The interpolation and extrapolation for the census data mentioned above are done after the adjustment.

If the correlation coefficient between two regressors is greater than 0.8 , multicollinearity may be a serious problem (Gujarati, 1995). According to Maddala (1992), multicollinearity can be detected by variance inflation factors (vif). A vif is a scaled version of the multiple correlation coefficients between variable $k$ and the rest of the independent variables. Specifically, vif $f_{k}=1 /\left(1-R_{k}^{2}\right)$, where $R_{k}$ is the multiple correlation coefficient. A rule of thumb is that multicollinearity may be a problem if the vif is greater than 10 (Gujarati, 1995). Although the number of bathrooms is a common structure characteristic used in the hedonic pricing literature, it was not included in the model because of the vif greater than 10 .

Previous studies have found that the logarithms of the continuous variables fit the model better than the linear form because the transformation captures the declining effect of the variables (Bin and Polasky, 2004; Iwata, Murao, and Wang, 2000; Mahan, Polasky, and Adams, 2000). We use the natural log transformations of continuous variables. After cleaning the individual housing data (deleting missing observations and unreasonably low and high prices), there are 5,843 observations. Detailed statistics for individual variables are reported in Table 1 .

(C) Southern Regional Science Association 2010. 
TABLE 1. Definitions and Sample Statistics

\begin{tabular}{|c|c|c|c|}
\hline Variable & Definition & Mean & Std. Dev. \\
\hline \multicolumn{4}{|c|}{ Dependent variable } \\
\hline PRICE & $\begin{array}{l}\text { Housing sales price in December } 2004 \text { dollars, } \\
(\$ 1,000)\end{array}$ & 150.99 & 78.71 \\
\hline \multicolumn{4}{|c|}{ Structural variables } \\
\hline$S Q F T$ & $\begin{array}{l}\text { Total finished structure square footage, } \\
(1,000 \text { square feet })\end{array}$ & 2.21 & 1.07 \\
\hline LOTSQFT & Lot square footage, (1,000 square feet) & 16.77 & 26.08 \\
\hline$A G E$ & Age of house in years, (year) & 2.02 & 2.11 \\
\hline$B E D R M$ & Number of bedrooms, (count) & 3.26 & 1.19 \\
\hline FIREPLC & 1 if a house has fireplace(s) & 0.73 & \\
\hline$B R I C K$ & 1 if a house has brick exterior walls & 0.28 & \\
\hline \multicolumn{4}{|c|}{ Neighborhood variables } \\
\hline TRAVEL & Average travel time to work in 2000 , (minutes) & 22.43 & 3.75 \\
\hline$H V A L U E$ & Median housing value in $2000,(\$ 1,000)$ & 135.91 & 66.37 \\
\hline PCINC & Per capita income in 2000 , ( $\$ 1,000$ per resident $)$ & 27.25 & 10.57 \\
\hline UNEMP & Unemployment rate in 2000 , (percentage) & 0.03 & 0.02 \\
\hline$A C T$ & American College Testing & 21.25 & 1.30 \\
\hline$K N O X V L$ & 1 if a house is within City of Knoxville & 0.14 & \\
\hline FARRGT & 1 if a house is within Town of Farragut & 0.09 & \\
\hline
\end{tabular}

(C) Southern Regional Science Association 2010. 
TABLE 1. Definitions and Sample Statistics (Continued)

\begin{tabular}{|c|c|c|c|}
\hline Variable & Definition & Mean & Std. Dev. \\
\hline \multicolumn{4}{|c|}{ Distance variables } \\
\hline$G O L F$ & Distance to nearest golf course, $(1,000$ feet $)$ & 20.44 & 9.28 \\
\hline$M A L L$ & Distance to the West Town Mall, (1,000 feet) & 41.14 & 23.04 \\
\hline$R A I L$ & Distance to nearest railroad, (1,000 feet) & 7.62 & 6.08 \\
\hline GREEN & Distance to nearest greenway, $(1,000$ feet $)$ & 9.45 & 5.94 \\
\hline$L A K E$ & Distance to nearest lake, $(1,000$ feet $)$ & 25.82 & 19.33 \\
\hline$C B D$ & Distance to nearest CBD, (1,000 feet $)$ & 52.57 & 19.09 \\
\hline \multicolumn{4}{|c|}{ Urban growth boundary variables } \\
\hline$T U G B$ & 1 if a house is sold after UGB implementation & 0.21 & \\
\hline$B U F F E R$ & $\begin{array}{l}1 \text { if a house is within a half mile buffer outside of } \\
\text { the City of Knoxville }\end{array}$ & 0.39 & \\
\hline $\begin{array}{l}T U G B^{*} \\
L U G B\end{array}$ & $\begin{array}{l}1 \text { if house is within UGB and sold after UGB } \\
\text { implementation }\end{array}$ & 0.03 & \\
\hline $\begin{array}{l}\text { TUGB* } \\
K N O X\end{array}$ & $\begin{array}{l}1 \text { if house is within the City of Knoxville and sold } \\
\text { after UGB implementation }\end{array}$ & 0.02 & \\
\hline $\begin{array}{l}\text { TUGB* } \\
\text { FARRGT }\end{array}$ & $\begin{array}{l}1 \text { if house is within the Town of Farragut and sold } \\
\text { after UGB implementation }\end{array}$ & 0.02 & \\
\hline$Y 1998$ & 1 if a house is sold in 1998 (reference) & 0.10 & \\
\hline$Y 1999$ & 1 if a house is sold in 1999 & 0.13 & \\
\hline$Y 2000$ & 1 if a house is sold in 2000 & 0.15 & \\
\hline$Y 2001$ & 1 if a house is sold in 2001 & 0.21 & \\
\hline$Y 2002$ & 1 if a house is sold in 2002 & 0.13 & \\
\hline$Y 2003$ & 1 if a house is sold in 2003 & 0.15 & \\
\hline$Y 2004$ & 1 if a house is sold in 2004 & 0.14 & \\
\hline
\end{tabular}

The average selling price was $\$ 150,990$, with a maximum sale price of $\$ 500,000$. A typical home has about 2,100 square feet of finished area, 16,770 square feet or 0.38 acres of lot area, and 3 bedrooms. About 73 percent of the homes have a fireplace and about 28 percent have all-brick exterior walls. Average travel time to work is 22.43 minutes, per capita income is $\$ 27,250$, and the unemployment rate is 3 percent.

(C) Southern Regional Science Association 2010. 


\section{EMPIRICAL MODEL}

Drawing on the hedonic price theory (Court, 1939; Griliches, 1961; Lancaster, 1966; Rosen, 1974) and the theoretic framework developed above, the housing price equation can be expressed as:

$$
y_{i}=f\left(\mathbf{x}_{i}^{\prime} \boldsymbol{\beta}, \varepsilon_{i}\right)
$$

where, for house $i, y_{i}$ is the sale price, $x_{i}$ is a vector of explanatory variables that includes housing characteristics (structural, distance, and neighborhood) and growth policies (i.e., UGB) $\beta$ is a conformable parameter vector, and $\varepsilon_{i}$ is an error term capturing random disturbances. The hypothesis for the higher premium of land price within the UGA, reflected in newly developed houses, is addressed by estimating the effect and testing for the statistical significance of the interaction dummy variable (indicating in or outside of UGA and houses built and sold before or after the implementation of UGB) in the hedonic price equation.

Although economic theory does not provide guidance on selecting a best functional form for the hedonic price function in Equation (4), a nonlinear functional form, such as the semi-log, is generally believed to be appropriate (Freeman, 2003). The Box-Cox (BC) transformation, which includes the linear and semi-log forms as constrained cases, has also been used in the hedonic price literature because of its functional form flexibility. Cropper, Deck, and McConnell (1988) first used the BC transformation in hedonic estimation and it has been similarly used in a number of subsequent studies, including Lutzenhiser and Netusil (2001), who used the BC transformation in estimating the effect of open space on housing prices. A variance-stabilizing device, the $\mathrm{BC}$ transformation accommodates non-normality of the random errors. A model with a BC-transformed dependent variable $\left(y_{i}\right)$ is formulated as:

$$
\left(y_{i}^{\lambda}-1\right) / \lambda=\mathbf{x}_{i}^{\prime} \boldsymbol{\beta}+\varepsilon_{i},
$$

where $\lambda$ is the transformation parameter to be estimated and the error term $\varepsilon_{i}$ has a normal distribution with mean 0 and variance $\sigma_{i}^{2}$. The sample likelihood function for an independent sample of $n$ observations is

$$
L=\prod_{i=1}^{n} y_{i}^{\lambda-1} \sigma_{i}^{-1} \phi\left\{\left[\left(y_{i}^{\lambda}-1\right) / \lambda-\mathbf{x}_{i}^{\prime} \beta\right] / \sigma_{i}\right\},
$$

where $y_{i}^{\lambda-1}$ is the Jacobian of transformation from $\varepsilon_{i}$ to $y_{i}$ and $\phi(\cdot)$ is the probability density function of the univariate standard normal distribution.

The assumption of homoskedastic errors, which amounts to $\sigma_{i}^{2}=\sigma^{2}$ for all $i$, may be questionable, as the literature suggests that error variance may relate to lot size and age of the structure (Fletcher, Gallimore, and Mangan, 2000; Goodman and Thibodeau, 1995; Mahan, Polasky, and Adams, 2000). Though the BC transformation of the dependent variable mitigates heteroskedasticity in the error terms and use of robust standard errors of coefficient estimates would allow robust statistical inference with arbitrary forms of heteroskedasticity, it is useful to accommodate potentially residual heteroskedasticity in the error variances. One approach is to specify the heteroscedastic error standard deviation explicitly. Here we parameterize the error standard deviation such that:

(C) Southern Regional Science Association 2010. 


$$
\sigma_{i}=\exp \left(\mathbf{z}_{i}^{\prime} \gamma\right)
$$

where $z_{i}$ is a vector of variables including a constant term, lot size, finished square footage, age of the structure, and the number of bedrooms, and $\gamma$ is a conformable parameter vector. The model, with parameters $\beta, \gamma$ and $\lambda$, can be estimated by the maximum likelihood method, based on the sample likelihood function defined in equations (6) and (7).

Global Moran's Index (Moran, 1948) is used to measure spatial autocorrelation in the model. The index is a measure of the overall spatial relationship across geographical units and is defined as:

$$
I=n \sum_{i=1}^{n} \sum_{j=1}^{n} w_{i j}\left(y_{i}-\bar{y}\right)\left(y_{j}-\bar{y}\right) /\left(\sum_{i=1}^{n} \sum_{j=1}^{n} w_{i j}\right) \sum_{i=1}^{n}\left(y_{i}-\bar{y}\right)^{2},
$$

where $n$ is the sample size, $y_{i}$ is the residual of house $i$ with sample mean $\bar{y}$, and $w_{i j}$ is the distance-based weight which is the inverse distance between houses $i$ and $j$. The $I$-value is similar to Pearson's sample correlation coefficient and varies between -1 and 1 in most cases (Goodchild, 1986).

\section{RESULTS}

To verify the existence of spatial error autocorrelation, Moran's Index statistics (I-value) for residuals of the heteroscedastic BC model were calculated. The $I$-value of the residual from the model was fairly low at 0.05 . Nevertheless, the $I$-value of the model was still statistically significant at the 1 percent level signifying spatial error autocorrelation in the residuals of the model. This result implies that although the inclusion of the median housing value significantly mitigates spatial autocorrelation, it does not fully address it and, thus, the statistical results should be interpreted with some caution.

A likelihood-ratio (LR) test was carried out to determine whether the empirical model should be estimated by the heteroscedastic $\mathrm{BC}$ model against the homoskedastic $\mathrm{BC}$ model or the semilog model. Denote the maximum log-likelihoods for the heteroscedastic BC model, homoskedastic $\mathrm{BC}$ model, or semi-log model as $f_{e}, f_{o}$, and $f_{l}$, with corresponding numbers of parameters $k_{e}, k_{o}$, and $k_{l}$. Then, the LR statistics $2\left(f_{e}-f_{o}\right), 2\left(f_{e}-f_{l}\right)$ is chi-square distributed with $\left(k_{e}-k_{o}\right)$ and $\left(k_{e}-k_{l}\right)$ degrees of freedom. The homoskedastic BC model and semi-log model were rejected with $p$-value $<0.001$ and degrees of freedom as 6 and 7 , respectively. The empirical model is therefore estimated with the heteroscedastic BC model by the maximum likelihood procedure, using lot square footage, finished square footage, age of the structure, and number of bedrooms to accommodate heteroskedasticity in the error terms (see equation 3). The parameter estimates, along with their robust standard errors (White, 1982), are presented in Table $2 .^{3}$

\footnotetext{
${ }^{3}$ The BC model with homoskedastic errors and the commonly used semi-log model were also estimated during preliminary analysis. These restricted models were rejected by likelihood-ratio tests and generally suggested different marginal effects of explanatory variables. Results for these restricted models are available upon request.
} 
TABLE 2. Maximum-Likelihood Estimation of Hedonic Housing Price Equation: The Heteroskedastic Box-Cox Model

\begin{tabular}{|c|c|c|}
\hline \multirow[b]{2}{*}{ Variable } & \multicolumn{2}{|c|}{ Coefficient } \\
\hline & Estimate & Standard Error \\
\hline$\overline{\text { CONSTANT }}$ & $-59.12 * * *$ & 7.00 \\
\hline \multicolumn{3}{|l|}{ Structural variables } \\
\hline $\ln (\mathrm{SQFT})$ & $9.33 * * *$ & 0.76 \\
\hline $\ln ($ LOTSQFT $)$ & $0.87 * * *$ & 0.11 \\
\hline AGE & $-0.33 * * *$ & 0.08 \\
\hline $\mathrm{AGE}^{2}$ & 0.00 & 0.01 \\
\hline BEDRM & -0.90 & 0.70 \\
\hline $\mathrm{BEDRM}^{2}$ & $0.24 *$ & 0.13 \\
\hline FIREPLC & $1.16^{* * *}$ & 0.11 \\
\hline BRICK & $1.37 * * *$ & 0.17 \\
\hline \multicolumn{3}{|c|}{ Neighborhood variables } \\
\hline $\ln (\mathrm{TRAVEL})$ & $0.90 * * *$ & 0.30 \\
\hline $\ln (\mathrm{HVALUE})$ & $1.55 * * *$ & 0.26 \\
\hline $\ln (\mathrm{PCINC})$ & $0.99 * * *$ & 0.27 \\
\hline UNEMP & $-11.26 * * *$ & 1.39 \\
\hline $\ln (\mathrm{ACT})$ & $3.82 * * *$ & 1.30 \\
\hline KNOXVL & $-1.96^{* * *}$ & 0.21 \\
\hline FARRGT & $3.17 * * *$ & 0.40 \\
\hline \multicolumn{3}{|l|}{ Distance variables } \\
\hline $\ln (\mathrm{GOLF})$ & $-0.32 * * *$ & 0.12 \\
\hline $\ln (\mathrm{MALL})$ & $-1.08 * * *$ & 0.13 \\
\hline $\ln (\mathrm{RAIL})$ & $0.33 * * *$ & 0.05 \\
\hline $\ln (\mathrm{GREEN})$ & 0.00 & 0.06 \\
\hline $\ln (\mathrm{LAKE})$ & $-0.15^{* *}$ & 0.07 \\
\hline $\ln (\mathrm{CBD})$ & $-1.95 * * *$ & 0.24 \\
\hline \multicolumn{3}{|c|}{ Urban growth boundary variables } \\
\hline TUGB*LUGB & $0.50 * *$ & 0.23 \\
\hline TUGB*KNOX & 0.15 & 0.21 \\
\hline TUGB*FARRGT & 0.84 & 0.71 \\
\hline Y1999 & -0.15 & 0.20 \\
\hline Y2000 & 0.08 & 0.19 \\
\hline
\end{tabular}

(C) Southern Regional Science Association 2010. 
TABLE 2. Maximum-Likelihood Estimation of Hedonic Housing Price Equation (Continued)

\begin{tabular}{lcc}
\hline & \multicolumn{2}{c}{ Coefficient } \\
\cline { 2 - 3 } Variable & Estimate & Standard Error \\
\hline$Y 2001$ & $-0.46^{* *}$ & 0.20 \\
$Y 2002$ & $-0.55^{* *}$ & 0.22 \\
$Y 2003$ & $-0.60^{* *}$ & 0.25 \\
$Y 2004$ & $-1.08^{* * *}$ & 0.26 \\
Heteroskedastic specification & & \\
$\ln (L O T S Q F T)$ & $0.21^{* * *}$ & 0.01 \\
$\ln (S Q F T)$ & $1.10^{* * *}$ & 0.02 \\
$A G E$ & 0.01 & 0.01 \\
$A G E^{2}$ & $0.00^{* *}$ & 0.00 \\
$B E D R M$ & $-0.84^{* * *}$ & 0.07 \\
$B E D R M^{2}$ & $0.16^{* * *}$ & 0.01 \\
CONSTANT & $-7.93^{* * *}$ & 0.19 \\
$\lambda$ & $0.57^{* * *}$ & 0.02 \\
Log likelihood & -28518.73 & \\
\hline \hline
\end{tabular}

Notes: Standard errors are calculated from the robust covariance matrix.

Asterisks denote statistical significance at the $1 \%$ percent $(* * *), 5 \%$ percent $(* *)$, and $10 \%$ percent $(*)$ levels.

The coefficient of the interaction term, $T U G B * L U G B$ is positive and statistically significant at the 5 percent level. This result implies that the implementation of the UGB significantly increased PRICE within the UGB relative to outside of the UGB, ceteris paribus. This finding supports the hypothesis that the values of newly developed houses after the implementation of UGB are likely to be higher in the UGA than outside. This also confirms that a higher premium of land price is derived from higher present values of the expected rental stream from undeveloped land in the UGA. The dummy variables that indicate years after UGB implementation are all negative and statistically significant at the 5 percent level. This is evidence that the increasing housing prices caused by UGB implementation were not affected by a time trend of the housing market.

The other interaction variables, $T U G B^{*} K N O X$ and $T U G B * F A R R G T$, are not statistically significant at the 10 percent level, which generally implies that there is no significant effect of the UGB on the difference between the housing prices inside and outside of jurisdiction boundaries. That is, the increased housing prices during the four years after the UGB was implemented were spatially concentrated within the UGB, but were not associated with jurisdiction boundaries of city and town.

The coefficients of most structural variables are statistically significant at the 1 percent level and the signs are generally expected. The effects of these structural variables are comparable with those reported in the literature (e.g., Bin and Polasky, 2004). The coefficient of

(C) Southern Regional Science Association 2010. 
TRAVEL is positive and statistically significant at the 1 percent level, suggesting that an increase in travel time to work is associated with higher housing prices. Travel time is expected to represent ease of access to work, but we suspect that concentration of more expensive houses (40 percent more expensive than the average) and greater travel time to work (10 percent greater than the average) in the Town of Farragut may have contributed to the reversed sign. This may reflect residents' stronger preferences for urban-fringe communities with greater natural amenities over the convenience of ease of access to work. It is also consistent with low-density and non-contiguous development along the urban-rural fringe in the United States (Wu, 2006). The coefficient of HVALUE is positive and statistically significant at the 1 percent level. This reflects significant neighborhood effects of housing value on housing price and confirms that the median housing value at the level of census-block groups mitigates the effects of spatial dependence. As expected, the coefficient of UNEMP suggests that lower unemployment rates are associated with higher house values. Consistent with previous findings about school accountability ratings and house values, the coefficient of $A C T$ is positive and statistically significant at the 1 percent level (Kane, Staiger, and Samms, 2003). This implies that average American College Testing (ACT) scores by high school districts have positive effects on housing prices.

The dummy variables KNOXVL and FARRGT are significant at the 1 percent level. Housing price is lower if the house is located within the City of Knoxville whereas it is higher if the house is located within the Town of Farragut. This reflects the fact that there are more expensive houses in the Town of Farragut. Though other factors may contribute, the lower housing price within the City of Knoxville is likely due to the perception that the value of additional public services provided to property owners within the city limits does not fully compensate for the higher city property taxes.

Five of the distance variables are statistically significant at the 1 percent level. A decrease in distance to the closest golf course increases housing prices, which is consistent with previous hedonic-price literature. A decrease in distance to the West Town Mall, which reflects the ease of access to a commercial area, increases PRICE, as do decreases in the distance to a lake and to the downtown. Greenways and lakes are environmental amenities that make nearby housing more attractive. Although proximity to a lake is associated with higher housing prices, the distance to the Greenway is not statistically significant. The distance to the nearest railroad is positive and statistically significant at the level of 1 percent. This is likely due to noise as a disamenity or inconvenience.

\section{CONCLUSIONS}

This study tests whether the higher present value of expected rental streams of undeveloped land in the UGA influences the effect of the UGB on the values of newly developed houses in Knoxville and Knox County. The positive and statistically significant effects of $T U G B^{*} L U G B$ on PRICE implies that the implementation of an UGB significantly increased PRICE within the UGA relative to outside of the boundary, ceteris paribus. This finding verifies the hypothesis that the values of newly developed houses, after the implementation of an UGB, are likely to be higher in the UGA than those outside of UGA. This confirms the theory of the price effects of UGBs by Knapp (1985). In contrast, the statistical insignificance of other interaction terms, $T U G B^{*} K N O X$ and $T U G B^{*} F A R R G T$ implies that the UGB effect is not associated with jurisdiction boundaries of the city and town.

(C) Southern Regional Science Association 2010. 
There have been conflicting reports on whether or not the policy of restricting growth through site-supply restrictions such as UGBs increases housing prices. The inner city neighborhoods have seen significantly higher housing prices in Portland. Similar to the case of Portland, the UGB effect on housing prices in Knoxville is associated with supply restriction through more stringent rezoning conditions in the UGA. Because it is unclear how rezoning conditions vary, future studies need to assess the likelihood of rezoning inside and outside of the boundary and the effects of the UGB on rezoning decisions.

While the hedonic property price method is used to test the effect of the UGB on the values of newly developed houses, it is important to note that the method provides only a measure of the relationship in the overall areas. For example, the UGB in Knoxville may have site-specific effects on housing prices depending on the type of areas (i.e., urbanized area with not much expectation of growth and area of rural-urban interface with dynamic development). In order to test the null hypothesis evaluating the uncertainties of the different consequences of the UGB in different types of areas, the structure of local real estate submarkets needs to be understood. For this reason, estimates from the hedonic house price model need to be interpreted carefully.

\section{REFERENCES}

Anselin, Luc and Nancy Lozano-Gracia. (2008) "Errors in Variables and Spatial Effects in Hedonic House Price Models of Ambient Air Quality," in Giuseppe Arbia and Badi H. Baltagi, eds., Spatial Econometrics: Methods and Applications. Physica-Verlag: Heidelberg, pp. 5-34.

Bin, Okmyung, and Stephen Polasky. (2004) "Effects of Flood Hazards on Property Values: Evidence Before and After Hurricane Floyd," Land Economics, 80, 490-500.

Bureau of Labor Statistics. (2006) Available at: http://www.bls.gov/, June.

Chan, Stephen. (2004) "Drawing the Line: The Effect of Urban Growth Boundaries on Housing Prices in the San Francisco Bay Area," Public Policy Center, Stanford University Working Paper.

Cho, Seong-Hoon, JunJie Wu, and William G. Boggess. (2003) "Measuring Interactions among Urban Development, Land Use Regulations, and Public Finance," American Journal of Agricultural Economics, 85, 988-999.

Court, Andrew T. (1939) "Hedonic Price Indexes with Automotive Examples," in The Dynamics of Automobile Demand. General Motors Corporation: New York.

Cropper, Maureen L., Leland D. Deck, and Kenneth E. McConnell. (1988) "On the Choice of Functional Form for Hedonic Price Functions," Review of Economics and Statistics, 70, $668-675$.

Downs, Anthony. (2002) "Have Housing Prices Risen Faster in Portland Than Elsewhere?" Housing Policy Debate, 13, 7-31.

Environmental System Research Institute (ESRI). (2004) Available at: http://www.esri.com/, March.

Fletcher, Mike, Paul Gallimore, and Jean Mangan. (2000) "Heteroscedasticity in Hedonic House Price Model," Journal of Property Research, 17, 93-108.

(C) Southern Regional Science Association 2010. 
Freeman, A Myrick, III. (2003) The Measurement of Environmental and Resource Values: Theory and Methods. Resources for the Future: Washington, D.C.

GeoLytics. (1990) Long Form in 2000 Boundaries. Available at: http://www.geolytics.com/ USCensus,Census-1990-Long-Form-2000-Boundaries,Data,Methodology,Products.asp, August.

Glaeser, Edward L., Joseph Gyourko, and Raven E. Saks. (2006) "Urban Growth and Housing Supply," Journal of Economic Geography, 6, 71-89.

Goodchild, Michael F. (1986) Spatial Autocorrelation. CATMOG 47. Geo Books: Norwich, United Kingdom.

Goodman, Allen C. and Thomas G. Thibodeau. (1995) "Age-Related Heteroscedasticity in Hedonic House Price Equations," Journal of Housing Research, 6, 25-42.

Griliches, Zvi (1961) "Hedonic Price Indexes for Automobiles: An Econometric Analysis of Quality Change," in Price Statistics of the Federal Government. National Bureau of Economic Research: New York, pp. 173-196.

Gujarati, Damodar N. (1995) Basic Econometrics, $3^{\text {rd }}$ Edition. McGraw-Hill International Editions: New York.

Hushak, Leroy. (1975) “The Urban Demand for Urban-Rural Fringe Land,” Land Economics, 51, $112-123$.

Iwata, Shigeru, Hiroshi Murao, and Qiang Wang. (2000) "Nonparametric Assessment of the Effects of Neighborhood Land Uses on the Residential House Values," in Thomas B. Fomby and R. Carter Hill, eds., Advances in Econometrics: Applying Kernel and Nonparametric Estimation to Economic Topics, Vol. 14. JAI Press: Greenwich, CT, pp. 229-257,

Kane, Thomas J., Douglas O. Staiger, and Gavin Samms. (2003) "School Accountability Ratings and Housing Values," in William G. Gale and Janet R. Pack, eds., Brookings-Wharton Papers on Urban Affairs. Brookings Institution Press: Washington, DC., pp. 83-137.

Kelejian, Harry H., and Ingmar R. Prucha. (2007) "The Relative Efficiencies of Various Predictors in Spatial Econometric Models Containing Spatial Lags," Regional Science and Urban Economics, 37, 363-374.

Knapp, Gerrit J. (1985) "The Price Effects of Urban Growth Boundaries in Metropolitan Portland, Oregon," Land Economics, 61, 26-35.

Lancaster, Kelvin J. (1966) “A New Approach to Consumer Theory,” Journal of Political Economy, 74, 132-157.

Lutzenhiser, Margot, and Noelwah R. Netusil. (2001) “The Effect of Open Spaces on a Home's Sale Price," Contemporary Economic Policy, 19, 291-298.

Maddala, Gangadharrao S. (1992) Introduction to Econometrics. McMillan Publishing Company: New York.

Mahan, Brent L., Stephen Polasky, and Richard M. Adams. (2000) "Valuing Urban Wetlands: A Property Price Approach," Land Economics, 76, 100-113.

(C) Southern Regional Science Association 2010. 
McMillen, Daniel. (1989) "An Empirical Model of Urban Fringe Land Use," Land Economics, $65,138-145$.

Moran, Patrick and Alfred Pierce. (1948) "The Interpretation of Statistical Maps," Journal of the Royal Statistical Society, Series B, 10, 243-251.

Metropolitan Planning Commission (MPC). (2001) Tennessee Public Chapter 1101: Growth Plan for Knoxville, Knox County, and Farragut, Tennessee. Available at: http://www.knoxmpc.org, August.

National Oceanic and Atmospheric Administration (NOAA). (2003) East Tennessee Ozone Study. Available at: http://www.atdd.noaa.gov/etos.htm, August.

Nelson, Arthur C. (1986) "Using Land Markets to Evaluate Urban Containment Programs," Journal of the American Planning Association, 52, 156-171.

Office of Federal Housing Enterprise Oversight (OFHEO). (2006) Available at: http://www.ofheo.gov, August.

Phillips, Justin, and Eban Goodstein. (2000) "Growth Management and Housing Prices: The Case of Portland, Oregon,” Contemporary Economic Policy, 18, 334-344.

Porter, Douglas R. (2002) Tennessee's Growth Policy Act: Purposes, Implementation, and Effects on Development. Available at: http://www.realtor.org/SG3.nsf/files/ tengrowthpol.pdf/\$FILE/tengrowthpol.pdf, July.

Rosen, Sherwin. (1974) "Hedonic Prices and Implicit Markets: Product Differentiation in Pure Competition," Journal of Political Economy, 82, 34-55.

Vanderbilt Center for Environmental Management Studies (VCEMS). (2002) The Clean Air Challenge: Improving Tennessee's Air Quality By Addressing the Contribution of Motor Vehicles Miles Traveled to Ozone Pollution. Available at: http://www.vanderbilt.edu/vcems/tcl/tclair.pdf, August.

White, Halbert. (1982) "Maximum Likelihood Estimation of Misspecified Models," Econometrica, 50, 1-25.

Wu, JunJie. (2006) "Environmental Amenities, Urban Sprawl, and Community Characteristics," Journal of Environmental Economics and Management, 52, 527-547.

C) Southern Regional Science Association 2010. 